\title{
VIDEO TRANSMISSION OVER WIRELESS NETWORKS REVIEW AND RECENT ADVANCES
}

\author{
Diaa Eldein Mustafa Ahmed \\ Faculty of Computer Science \\ and Information Technology, \\ Sudan University for Science \\ and Technology, Sudan \\ diamahmed@gmail.com
}

\author{
Othman O. khalifa \\ Department of Electrical \\ and Computer \\ Engineering, International \\ Islamic University \\ Malaysia \\ khalifa@iium.edu.my
}

\author{
Abdirisaq M. Jama \\ Department of Electrical \\ and Computer \\ Engineering, International \\ Islamic University \\ Malaysia
}

\begin{abstract}
Video transmission over wireless networks is considered the most interesting application in our daily life nowadays. As mobile data rates continue to increase and more people rely on wireless transmission, the amount of video transmitted over at least one wireless hop will likely continue to increase. This kind of application needs large bandwidth, efficient routing protocols, and content delivery methods to provide smooth video playback to the receivers. Current generation wireless networks are likely to operate on internet technology combined with various access technologies. Achieving effective bandwidth aggregation in wireless environments raises several challenges related to deployment, link heterogeneity, Network congestion, network fluctuation, and energy consumption. In this work, an overview of technical challenges of over wireless networks is presented. A survey of wireless networks in recent video transmission schemes is introduced. Demonstration results of few scenarios are showed.
\end{abstract}

Keywords: Video coding, video compression, wireless video transmission

\section{INTRODUCTION}

Video has been an important media for communications and entertainment for many decades. Initially Communication ways have changed from smoke signal to digital signals. These days technology is improving such that people can talk face to face over $4 \mathrm{G} / \mathrm{Wi}-\mathrm{Fi}$ network using computers without bothering distance between them. Though technically all this service uses internet for transmitting voice over network. Now these days we have so many technologies that support communication over internet like chatting, live video chatting, and calling from one computer to other [1]. The evolution of internet has also increased the demand for multimedia content. Multimedia is the media that uses multiple forms of information content and information processing (e.g. text, audio, video, graphics, animation, interactivity) to inform or entertain the user. Multimedia means that represented the computer information through audio, video, image, graphics and animation in addition to traditional media [2]. It is possible to achieve higher aggregate data transmission rate while choosing several spatially distributed paths, thus benefiting from the spatial reuse of a wireless channel. That in its turn allows achieving higher video quality. Multipath routing allows the establishment of multiple paths between a single source and single destination node. It is typically increase the reliability of data transmission or to provide load balancing. Streaming media may be either real time or ondemand. On demand streams are stored on the server and based on the user requirement content is transmitted. Then, user may play video or may download the video for viewing purpose. Real time stream are only available on a some particular time. For example, when the event is occurring and user can record the video .Video Communication may be point to point communication, multicast or broadcast. Video may be pre-encoded or may be encoded in real time [2]

Upon the client's request, a streaming server retrieves compressed video/audio data from storage devices and then the application-layer QoS control module adapts the video/audio bit-streams according to the network status and
QoS requirements [3]. After the adaptation, the transport protocols packetize the compressed bit-streams and send the video/audio packets to the Internet[4]. Packets may be dropped or experience excessive delay inside the Internet due to congestion. For packets that are successfully delivered to the receiver, they first pass through the transport layers and then are processed by the application layer before being decoded at the video/audio decoder[5]. To achieve synchronization between video and audio presentations, media synchronization mechanisms are required.

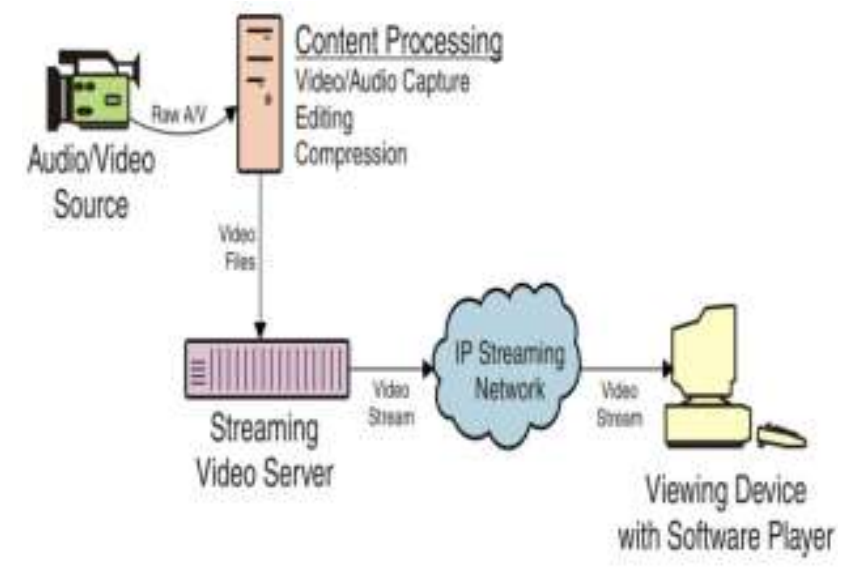

Figure .1 Internet Video Streaming Architecture

\section{VIDEO STREAMING}

Video streaming over computer networks is considered to become the most interesting application in the near future. There are three types of delivery methods of streaming media; Streaming Stored Audio and Video, Streaming Live Audio and Video and Real-Time Interactive Audio and Video. Figure 2 show the overall Architecture for Video Streaming [6]. 


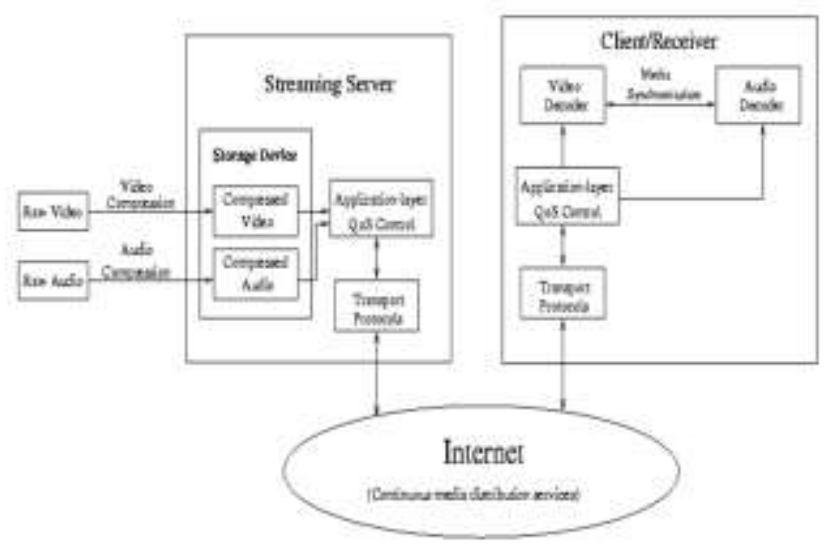

Figure 2 Architecture for Video Streaming [5]

This kind of application needs large bandwidth, efficient routing protocols, and content delivery methods to provide smooth video playback to the receivers. Video streaming systems are classified into two categories including:

\subsection{Live video Streaming}

In live video streaming, synchronized streams are played back in all nodes, and all users watch the same video frames simultaneously.

\subsection{Video on Demand}

$(\mathrm{VoD})$ streaming, users watch different video frames of the same video stream at a given instant of time. In other words, the playbacks of the same video streams on different clients are not synchronized for a VoD streaming. Real-time multimedia data applications, such as video streaming and video telephony, are regarded as "killer applications" in the emerging wireless networks. Video applications usually involve a large volume of data transmitted in a time sensitive fashion [7]. However, the underlying wireless networks only provide time-varying and limited bandwidth, high data error rate, packet delay and jitter. Extensive research has been done on either video data coding algorithms or wireless network protocols. But the traditional layered network model limits the video transmission over wireless networks because it tries to separate information and functions between different layers[8]. To enable more efficient real-time data transmission over dynamic wireless environments, the applications and underlying wireless networks should cooperate in order to share information and optimize the transmission process dynamically. In this parts reviews the state-of-the-art research efforts on video coding, error control, and rate control algorithms. New cross-layer algorithms are presented which coordinate the algorithms at different layers in order to get better performance than using them separately. The cross-layer rate control algorithm matches the application's future bandwidth requirement to the available bandwidth in the network so that an optimum data transmission rate can be selected. In cross-layer architecture, layers exchange information and jointly optimize in order to improve the overall performance[9]. Also the cross-layer error control algorithm, lower layers are responsible for error detection and fast retransmission, while application layer conducts an adaptive error correction algorithm with the help of lower layers [10].

Multimedia services and applications became the driving force in the development and widespread deployment of wireless broadband access technologies and high speed local area networks. Mobile phone service providers are now offering a wide range of multimedia applications over high speed wireless data networks. People can watch live TV, stream on-demand video clips and place video telephony calls using multimedia capable mobile devices. The variety and quality of these applications are increasing every day. Mobile devices will soon support capturing and displaying high definition video. Similar evolution is also occurring in the local area domain. The video receiver or storage devices were conventionally connected to display devices using cables. By using wireless local area networking (WLAN) technologies, convenient and cable-free connectivity can be achieved. Media over wireless home networks prevents the cable mess and provides mobility to portable TVs.

However, there still exits challenges for improving the quality-of-service (QoS) of multimedia applications. Conventional service architectures, network structures and protocols lack to provide a robust distribution medium since most of them are not designed considering the high data rate and real-time transmission requirements of digital video[11].

\section{LITERATURE REVIEW AND RELATED WORK}

Many researchers are working on improving the video transmission over wireless network via different approaches Table. 2 shows some of the recent state of the art or contributions in this area, it is classified the video transmission schemes into three major schemes:

(A) Cross Layer Design Schemes(CLDS)

(B) Multiple Descriptions Coding Schemes(MDCS)

(C) Multipath Routing Schemes (MPRS)

(D) Resource Allocation Schemes(RAS)

Table.2 State of the art of the recent video transmission schemes

\begin{tabular}{|c|c|c|c|}
\hline Author(s) & Proposed Method & $\begin{array}{l}\text { Gained Results } \\
\text { (Contributions) }\end{array}$ & Limitation(s) \\
\hline $\begin{array}{l}\text { [15]- Vinod } \\
\text { B. and et al. } \\
\text { [2013] }\end{array}$ & $\begin{array}{l}\text { (1)-Without considering channel status } \\
\text { Condition } \\
\text { (2)-The video signal is encoded with the H.264 } \\
\text { coding technique at the frame rate of } 24 \text { frames } \\
\text { per second, with bit rate of } 100 \mathrm{kbps} \text {. } \\
\text { (3)-Develop methods to take care of resource } \\
\text { allocation in cooperative wireless sensor } \\
\text { networks (CWSNs). }\end{array}$ & $\begin{array}{l}\text { From this simulation result, we } \\
\text { observed that: rather than } \\
\text { encoding the frame itself, the } \\
\text { difference between current frame } \\
\text { and the previous frame is } \\
\text { encoded so that the amount of } \\
\text { information transmitted will be } \\
\text { drastically reduced. }\end{array}$ & $\begin{array}{l}\text { (1)-The frames can be } \\
\text { properly analyzed to assign } \\
\text { the security codes. } \\
\text { (2)-Since energy is the crucial } \\
\text { parameter in the cooperative } \\
\text { wireless sensor networks, the } \\
\text { resource allocated may be } \\
\text { controlled using cross layer } \\
\text { design based on the priority }\end{array}$ \\
\hline
\end{tabular}




\begin{tabular}{|c|c|c|c|}
\hline $\begin{array}{l}\text { [16] P. A. } \\
\text { Chaparro, and } \\
\text { et al.[2010] }\end{array}$ & $\begin{array}{l}\text { (1)- Presented DACME-SV, a novel QoS } \\
\text { framework to support scalable video } \\
\text { transmission over MANETs. } \\
\text { (2)- Benefits of using this novel solution that } \\
\text { combines the flexibility of the H.264/SVC } \\
\text { codec with distributed admission control } \\
\text { algorithms. } \\
\text { (3)-The strategy proposed allows to } \\
\text { dynamically adjust the video quality according } \\
\text { to end-to-end path conditions, thus optimizing } \\
\text { available resource usage. }\end{array}$ & $\begin{array}{l}\text { (1)- Experimental showed that } \\
\text { DACME-SV is able to improve } \\
\text { global performance by } \\
\text { decreasing the frequency of } \\
\text { interruptions on video } \\
\text { communications, while } \\
\text { simultaneously improving } \\
\text { fairness among users by favoring } \\
\text { similar conditions for QoS flows. } \\
\text { (2)-Channel utilization was also } \\
\text { improved with this strategy. }\end{array}$ & $\begin{array}{l}\text { As future work they plan to } \\
\text { introduce further } \\
\text { improvements to DACME- } \\
\text { SV by also including support } \\
\text { for end to-end delay bounds. }\end{array}$ \\
\hline $\begin{array}{l}\text { [17] Detti and } \\
\text { et al. [2010] }\end{array}$ & $\begin{array}{l}\text { (1)-Evaluated and demonstrated a technique for } \\
\text { streaming H.264 SVC video over a DDS } \\
\text { middleware. } \\
\text { (2)-The structure of the DDS data unit } \\
\text { designed by them was able to carry H.264 SVC } \\
\text { video-units. } \\
\text { (3)-Also they designed a receiver-driven rate- } \\
\text { control mechanism based on the DDS data unit, } \\
\text { which exploited specific DDS functionality. }\end{array}$ & $\begin{array}{l}\text { Their implementation showed } \\
\text { the effectiveness of their } \\
\text { mechanism in IEEE } 802.11 \\
\text { wireless scenario, comparing } \\
\text { their proposal with other } \\
\text { solutions. }\end{array}$ & $\begin{array}{l}\text { It is a demonstration work } \\
\text { with out explaining the theory } \\
\text { behind. }\end{array}$ \\
\hline $\begin{array}{l}\text { [18]Kalvein } \\
\text { Rantelobo, et } \\
\text { al. } \\
\text { [2012] }\end{array}$ & $\begin{array}{l}\text { (1)- Create Combined Scalable Video Coding } \\
\text { (CSVC) method that match the QoS of video } \\
\text { streaming service on wireless channel } \\
\text { (2)- Use Joint Scalable Video Model (JSVM) } \\
\text { amendment standard. } \\
\text { (3)- The proposed scheme has implemented on } \\
\text { Network Simulator II (NS2) for wireless } \\
\text { broadband network application. } \\
\text { (4)- This new scheme is an evaluation platform } \\
\text { for the implementation CSVC on a more } \\
\text { realistic simulation over wireless broadband } \\
\text { networks based on open-source program. } \\
\text { (5)- The results show that implementation of } \\
\text { CSVC on mode of the medium grain scalable } \\
\text { (MGS) outperforms coarse grain scalable } \\
\text { (CGS) mode. }\end{array}$ & $\begin{array}{l}\text { (1)-T his research proves that } \\
\text { CGS and MGS mode on video } \\
\text { transmission on wireless } \\
\text { broadband network (WLAN } \\
\text { IEEE } 802.11 \mathrm{e} \text { ) is implementable } \\
\text { on NS2 we 1l. } \\
\text { (2)-T he use of mode MGS gave } \\
\text { result t hat is more satisfactory } \\
\text { compared to CGS mode. } \\
\text { (3)-Investigated the impacts of } \\
\text { the use of MG S and CGS modes } \\
\text { on performance of this system } \\
\text { (4)-T he applications of MG S } \\
\text { mode on CSV C increases the } \\
\text { performance compared to CGS } \\
\text { mode. }\end{array}$ & $\begin{array}{l}\text { Video transmission based on } \\
\text { the CSVC over broadband } \\
\text { wireless network (WLAN } \\
\text { IEEE } 802.11 \mathrm{e} \text { ), simulated by } \\
\text { NS2 with ideal assumption } \\
\text { conditions. }\end{array}$ \\
\hline $\begin{array}{l}\text { [19] } \\
\text { Gopikrishnan. } \\
\text { R[2014] }\end{array}$ & $\begin{array}{l}\text { (1)-proposed a novel MAC-level multicast } \\
\text { protocol named REMP } \\
\text { (2)-In REMP, AP selectively retransmits } \\
\text { erroneous multicast frames and dynamically } \\
\text { adjusts MCS under varying channel conditions } \\
\text { based on the advanced feedback mechanism } \\
\text { from multicast receivers. } \\
\text { (3)- In addition, he proposed S-REMP, an } \\
\text { extended version of REMP, for efficient } \\
\text { delivery of scalable video over IEEE 802.11n } \\
\text { WLANs. }\end{array}$ & $\begin{array}{l}\text { (1)- Via extensive simulation } \\
\text { results, we proved the } \\
\text { effectiveness of the proposed } \\
\text { protocols enhances the } \\
\text { reliability and efficiency of } \\
\text { multicast transmissions in IEEE } \\
802.11 \mathrm{n} \text { WLANs. } \\
\text { (3)- In S-REMP, different layers } \\
\text { of scalable video can be } \\
\text { transmitted with different MCSs } \\
\text { to provide the minimal video } \\
\text { quality to all users while } \\
\text { providing a higher video quality } \\
\text { to users exhibiting better channel } \\
\text { conditions. }\end{array}$ & $\begin{array}{l}\text { In this work S-REMP to } \\
\text { guarantee minimal video } \\
\text { quality to all users in future } \\
\text { work to guarantee a maximal } \\
\text { video quality to all users. }\end{array}$ \\
\hline
\end{tabular}

\section{Result Analysis for Simulation Scenario}

In this simulation scenario, there are 9 QoS active stations transmitting data to one access point. There are 3 groups of stations with three stations each. The first group transmits video flow, while the second transmits voice flow and the third transmits best effort data flow. The same simulation parameters in Table 3 are used in this scenario.

In this scenario, the aim is to study the effect of varying the propagation distance on the performance of IEEE802.11e WLAN. The propagation distance was changed by varying the topology from 100 to 1000 square meters. All the QoS active stations move randomly within the coverage area of the access point. All the results are average over five simulations to overcome the errors occur when the stations move on the borders of the coverage area.

The second scenario shows the effect of varying the propagation distance on the average end-to-end delay and the packet loss ratio. These two performance metrics are affected the most in this simulation. Figure 7 illustrates the relationship between the average end-to-end delay and the change of topology. 
Table 3 Enhanced EDCA Simulation Parameters

\begin{tabular}{|l|l|l|l|}
\hline $\begin{array}{l}\text { Simulation } \\
\text { Parameter }\end{array}$ & Video & Voice & $\begin{array}{l}\text { Best } \\
\text { effort }\end{array}$ \\
\hline Transport Protocol & UDP & UDP & UDP \\
\hline $\mathrm{CW}_{\min }$ & 3 & 7 & 15 \\
\hline $\mathrm{CW}_{\max }$ & 7 & 15 & 1023 \\
\hline AIFSN & 1 & 2 & 3 \\
\hline Packet Size (bytes) & 1028 & 160 & 1500 \\
\hline Packet Interval (ms) & 10 & 20 & 12.5 \\
\hline Data rate (kbps) & 822.40 & 64 & 960 \\
\hline
\end{tabular}

In Figure 3, it is clearly shown that the average endto-end delay increases with the increase of the propagation distance from source to destination. However, the delay difference between the different flows is clear. This is due to the channel prioritization performed by EDCA and HCCA enhanced functions. The end-to-end delay value of the video flow is still acceptable even when the topology is 1000 square meters, while it is not for the voice and best effort data flows. More details and explanations are provided in the discussion sub-section.

Figure 4 shows the packet loss ratio change while varying the topology area. The packet drop has different starting value of topology area for different priorities.

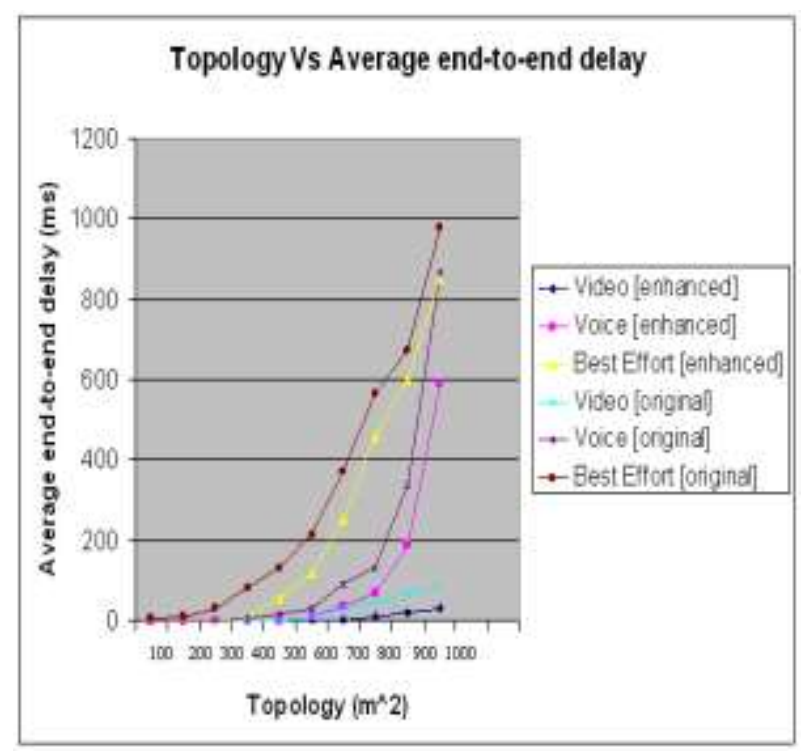

Figure 3: The effect of topology change on average end-to-end delay of three data flows (voice, video and best effort data) using original \& enhanced EDCA values.

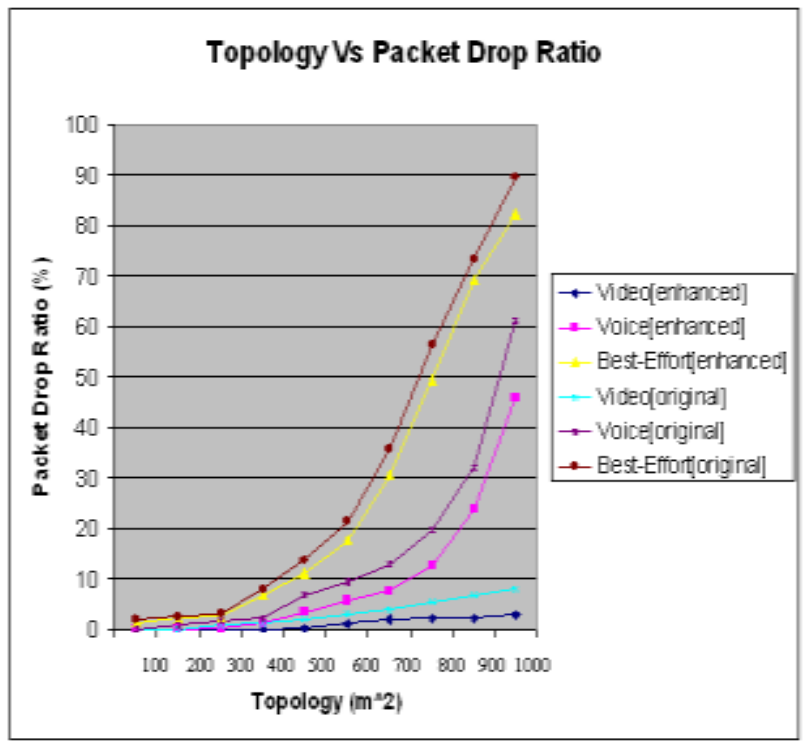

Figure 4: The effect of topology change on Packet Drop Ratio of three data flows (voice, video and best effort data) using original \& enhanced EDCA values.

For example, as shown in Figure 4; regarding the enhanced values, the packet drop for the video flow starts when the topology is 500 square meters, while it starts at 100 and 300 square meters for the best effort data and voice flows respectively. On the other hand, when the topology area is 1000 square meters, the differentiation between the three flows is much clearer concerning the packet drop ratio.

\section{CONCLUSION}

Video transmission over wireless networks and the internet is a challenging task due to the stringent QoS required by video applications and also affected by many channel impairments. By using a fast mode decision algorithm for H.264 intra prediction and an adaptive transmission control methods of video can gain good QoS and achieves 30\% to 60\% computation reduction on aspects of video coding, so that the stability and good qualities of video transmission can be ensured. Based on the above investigation the work can be continued in the following areas which includes efficient video coding, reliable wireless transmission, QoS, transmission rate, energy efficiency of handheld devices to improve the overall wireless video transmission system.

\section{REFERENCES}

[1] Nalini Bagal,and Shivani Pandita, A Review: Real-Time Wireless Audio-Video Transmission, International Journal of Emerging Technology and Advanced Engineering, Volume 5, Issue 4, April 2015, pp. 168170.

[2] Reena Boora and Veepin Kumar, Approaches to improve Video Transmission over Wireless Network in MANET, International Journal of Scientific Research Engineering \& Technology, Volume 3, Issue 3, June 2014, pp. 729732.

[3] Scott Pudlewski, Nan Cen, Zhangyu Guan, and Tommaso Melodia, Video Transmission Over Lossy Wireless Networks: A Cross-Layer Perspective, IEEE JOURNAL OF SELECTED TOPICS IN SIGNAL PROCESSING, VOL. 9, NO. 1, FEBRUARY 2015, pp. 6-22..

[4] Elkilani, W.S., Abdul-Kader, H.M. ," Performance of encryption techniques for real time video streaming " 
International Conference on Networking and Media Convergence, ICNM 2009, pp. $130-134$.

[5] Kamisetty Rao, Zoran Bojkovic, Dragorad Milovanovic, "Introduction to Multimedia Communications: Applications, Middleware, Networking", John Wiley and Sons Publications 2006.

[6] Behrang Barekatain, Mohd Aizaini Maarof, Alfonso Ariza Quintana and Alicia Triviño Cabrera " GREENIE: a novel hybrid routing protocol for efficient video streaming over wireless mesh networks", New Technologies and Research Trends for Wireless, Mobile and Ubiquitous Multimedia ,2013.

[7] Azzedine Boukerche " Handbook of Algorithms for Wireless Networking and Mobile Computing " ,chapman \& Hall/CRC Computer and information Science Series ,2006.

[8] G. Ding, X. Wu, and B. Bhargava. "Cross-Layer Algorithm for Video Transmission over Wireless Network." in Handbook of Algorithms for Mobile and Wireless Networking and Computing (A. Bourkerche, ed.), CRC Press, 2005.

[9] Srivastana, V., Motani, M.: Cross-layer design: a survey and the road ahead. IEEE Commun.Mag. 43(12), 112119 (2005)

[10] G. Ding, X. Wu and B. Bhargava, "Cross-layer Control of Real-time Data Transmission over Wireless Networks.", 2003

[11] Mehmet Umut Demircin, Robust Video Streaming Over Time-Varying Wireless Networks, PhD thesis, Georgia Institute of Technology August 2008.

[12] Pavlos Antoniou, Andreas Pitsillides, Vasos Vassiliou, "Adaptive Methods for the Transmission of Video Streams in Wireless Networks “, University of Cyprus , Department of Computer Science ,Networks Research Laboratory ,2002 .
[13] Imed Bouazizi,"Proxy Caching for RobustVideo Delivery over Lossy Networks ", PhD Dissertation ,2004.

[14] ITU-T Recommendation G.1010, End-user multimedia QoS categories, 2001.

[15] Vinod B Durdi, P. T. Kulkarni, and K. L. Sudha ," Robust Video Transmission over Wireless Networks Using Cross Layer Approach", Journal of Industrial and Intelligent Information Vol.1, No. 2, June 2013:

[16] P. A. Chaparro, J. Alcober J. Monteiro ,C. T. Calafate, J.C. Cano, P. Manzonill Supporting Scalable video transmission in MANETs through distributed admission control mechanisms \|18th Euromicro Conference on Parallel, Distributed and Network -based Processing 2010 IEEE DOI 10.1109/PDP.2010.44

[17] A. Detti, P. Loreti, N. Blefari-Melazzi, and F. Fedi, "Streaming H.264 scalable video over data distribution service in a wireless environment," in Proceedings of the IEEE International Symposium on A World of Wireless, Mobile and Multimedia Networks (WoWMoM '10), June 2010.

[18] Kalvein Rantelobo, Wirawan, G. Hendrantoro, A. Affandi, and Hua-An Zhao, "A New Scheme for Evaluating Video Transmission over Broadband Wireless Network “, Future Wireless Networks and Information Systems, LNEE 143, pp. 335-341, Springerlink.com (C) Springer-Verlag Berlin Heidelberg 2012

[19] Gopikrishnan.R , “An Efficient Real Time Video Multicasting Protocol and WLANs Cross-Layer Optimization in IEEE $802.11 \mathrm{~N}$ “, IJCSMC, Vol. 3, Issue. 2, February 2014, pg.811-814. 